\title{
Why We Get Sick and Old?
}

\author{
Vivina Siddhi* \\ Slovenian-born artist, NGO Mandala Transformation, USA.
}

*Corresponding author: Viviana Siddhi, Slovenian-born artist with American citizenship, NGO Mandala Transformation, Inc., California, USA.

\begin{abstract}
We can slow down and even reverse the effects of aging with a preventive health care that includes alternative approaches. It's never too late to start changing ourselves. Man needs a healthy body for a healthy mind, filed worth good thoughts. Physical fitness alone is not enough. Mental health is equally important. Together with the gross physical body everybody has a subtle body. One has to take good care of this subtle body also. For this, spiritual exercises will have to be performed which will help one to realize the purity of the heart, mind and soul. We have to practice human values for healthy living, too.
\end{abstract}

\section{Peace - Stress - Peace}

The greatest disease (or absence of ease) is the absence of peace of mind. When the mind gets peace, the body also will have health. We must pay attention to the emotions, feelings and motives that animate the individual. We should have good company. Bhagavan's Satya Sai Baba's statement is that falsehood, injustice, indiscipline, cruelty, hates form the dirt. Truth, Righteousness, Peace, Love these form the clean elements. If you inhale the pure air your mind will be free from evil and you will be mentally sturdy and physically strong.

Science is finding more and more that psychological stress has severe impacts on the body and mind. Stress can trigger depression and anxiety; it can trigger asthma attacks and strokes, it can set off heart-beat disturbances; it can irritate digestion and even cause ulcers; it can cause impotence in man and menstrual difficulties in women, it can trigger muscle twitches and nervous tics, and it cause the skin break out in various diseases. The modern lifestyle leads to stress, anger, depression and lack of time for spiritual work. Anger is a great cause of ill health, besides being dangerous for other reasons. We must conquer these negative emotions within us when they arise in the mind and try to think of something else than the circumstances that roused your anger, jealousy etc. Go for a long walk, do yoga, gym, ride a bike, and do activities that make you happy. Than you struggle less and win fast. Man does not take preventive measures; he allows things to worsen and then the disease is aggravated by fear, uncertainty and anxiety.

"Stress hormones - the "fight-or-flight" hormone adrenaline literally pour into our cardiovascular system when you're under stress, especially in situations involving anger or hostility. This sends your blood pressure sky-rocketing and it's implicated not only in heart disease but in heart attacks" [1]. It decreases in blood flow to the extremities, including the sexual organs; and a slowing of digestion. The "fight-or-flight" response also increases the level of the hormone cortisol, which reduces the activity of the immune system. Cortisol plays a useful role in the temporary reduction of inflammation. When the danger has passed, these systems return to normal in the relaxation response. However, in chronic stress, this physiological arousal persists, which can lead to a decrease in the activity of the immune system and continual anxiety.

When we dive through consciousness and we are exposed to the negative influences from other people who are meditating on us, we also get stressed out. Such kind of influences have very bad effects on our daily life. We make wrong decisions and destructions that are essential for entire life. Unfortunately, people who have opened third eye are sometimes paid to create destructions just to satisfy others wishes. They are imposing thoughts into the brains during sleep time. Instead to send another person positive affirmation for long, healthy and wealthy life they are analyzing and criticizing others, imposing dangerous illusions via thoughts and images. They are also trying to control others. This is not our natural state of mind. It is very unhealthy approach and against the natural law. Every human being has the right to have freedom to live in a healthy way.

If we can relieve stress, we can help keep our mind and body in youthful condition. When you feel better, you behave younger 
and you live younger. You have more optimism, more courage. By changing your lifestyle through diet, exercise and attitude - your biological age can be that of a younger person.

\section{Breath}

There are ranges of techniques for inducing the relaxation response such as: meditation, yoga, breathing exercises, muscle relaxation and hypnosis (deep relaxation state). All these methods led to decreases in oxygen consumption, respiration rate, and heart rate. In patients with high blood pressure, the blood pressure went down. "There was also decrease in the level of lactic acid in the blood, falling by around 40 percent within ten minutes of starting to meditate. Lactic acid is normally produced as a result of muscular activity, and in people prone to anxiety, it increases the likelihood of anxiety attacks" [2].

When the breath slows down and we have negative entity in the aura, this entity can create a feeling of "protection field"; however, it is causing an anxiety. It can trigger brain and causes stroke. Breathing techniques awakens Kundalini energy. Kundalini is described as a sleeping, dormant potential force in the human being. It is one of the components of an esoteric description of the subtle body, which consists of nadis (energy channels), chakras (psychic centers), prana (subtle energy), and Bindu (drops of essence). Ida, pingala and sushumna are the three major nadis or psychic energy channels responsible for the activation and rising of kundalini, known otherwise as the "serpent power". Slow and deep breathing reduces stress. We stay young when kundalini energy is speeding up in all chakras equally and stays this way.

Any kind of activity can be transformed into active meditation. One can learn active meditation via mandala's workshops that I teach over 30 years. We slow down; however, we do quality work without any stress.

\section{Indigenous People}

Indigenous people are very knowledgeable about power of thoughts via prayers. Unfortunately, most of them suffer and it's very hard for them to step out of struggling circle of psychic attacks. This is one of the main reasons that indigenous people are vulnerable for alcohol and drugs.

“For the tribes' people themselves, an essential element is the involvement of their shamans, their spiritual guides and the keepers of traditional tribal knowledge. A shaman is using a small pouch from around his neck. He shook out a fine, black powder into his palm and he uses the powerful snuff, made from tobacco, to "open up" the mind and reach the tribe's people using his thoughts. By performing traditional rituals, including dances, he and the other tribal shamans can build a protective wall with the spirits to keep miners' loggers and drug traffickers out of the forbidden territories. Through their spiritual work with their thoughts, they give them space, so they can live in peace" [3].

\section{Psychic Attacks}

We often hear people saying, "I am feeling low", I feel some kind of negativity", "this place is negative”, psychic interventions, cursing, jealousy etc. All these thoughts, words, feelings and emotions point towards a negative presence or a negative entity. They impact our lives physically, mentally, emotionally, and spiritually around the body. "These entities can become enmeshed in the aura, the energy field around the body. The emotional or physical trauma endured by a person can render the energy centers vulnerable. They are open like doors to allow entry and attachment by entity" said Dr. William J. Baldwin.

Holes in our aura can be created during surgeries, traumas, etc. When our aura is not whole, its ability to fight the negativity drastically reduces. With a prolonged period of suffering, long bouts of anger and extended periods of stress, all of this can create holes in the aura leading to easy invasion. Black magic and sorcery exist in every culture and proofs of the same exist widely. People who are unhappy with themselves on the first place and with others can send negative energy to bring misery to the victim. They will try to invade your space, time and stay with you, until is cleansed or to the end of one's life span.

Spirit possession or control by non-physical entity goes against our most basic human and spiritual rights. Unfortunately, they are coming from unhappy people who are lost in illusions and they are triggering our weak spots. These human beings can be very lovely and at the same time evil, too. It is a possibility both terrifying and preposterous.

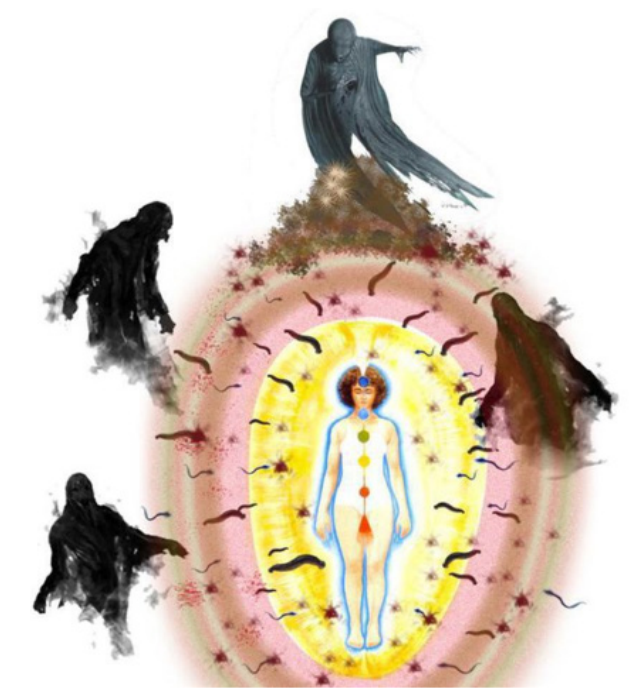

\section{Collective Patterns}

Sometimes, we have negative thoughts and believe systems that are not serving us, anymore. We can clear them out, erased, let go and replace with new healing patterns of thoughts and feelings. Than we can ripple out to the good of the collective consciousness. Very common collective patterns are: "I am too old. I am aging. I am not so flexible as I was when I was young." We can consciously replace them with: "I am young. I am not aging. I am flexible." Once the mind accepts this believe we actually stop aging.

When I was a teenager, I believed that aging is a disease and I do not want this kind of illness. Each year, I am over and over again surprised that this believes system really works. This leads to the next believe system that whatever we believe that we actually become. I realized that sometimes I have a hard time to eat only 
healthy food; however, if I surrender myself with like-minded "pure" people, it becomes a habit in easy manner.

\section{Discipline}

To enjoy good health, to bring true happiness to one's life, family, community, to bring peace at all, one must first discipline and control one's own mind. Regular yoga is one of the most important paths to learn discipline. In yoga, self-discipline is the commitment to the practice. With that we learn how to heal the body, mind and the soul.

"All of this evidence points toward a new way of thinking about physical activity. But exercise is not optional; it is essential, and weight loss is probably the one health benefit it largely fails to deliver. Our bodies are evolved to require daily physical activity, and consequently exercise does not make our bodies work more so much as it makes them work better. Research from lab has shown that physical activity has little effect on daily energy expenditure (Hadza hunter-gatherers burn the same number of calories every day as sedentary Westerners), which is one reason exercise is a poor tool for weight loss. Instead exercise regulates the way the body spends energy and coordinates vital tasks" [4].

\section{Yoga}

It is a matter of careful well-timed regulated discipline and it has to be climbed step by step, each step being used as a foothold for the next step. In this way we cultivate good character. If we trust in a higher power that is ready to come to help to your help, work is made easy. The hospitals should teach preventive measures also and try to educate people in methods of avoiding illness. To develop self-reliance is the best tonic. We can begin with little things that we can avoid causing annoyance to others. Purification of words leads to cleansing the mind. Such talk will cause no quarrel, no blood pressure. It promotes mutual respect and love.

"The Six Kriyas (cleansings) also called Shatkriyas, for the cleansing of the lower respiratory system, food, pipe, stomach, eyes, and the lower colon are - Dhauti, Basti, Neti, Nauli, Tratak and Kapalabhati" [5]. Purifications of the body are necessary for pure body, mind and spirit. Fault-finding which causes negativism will not help self-purification. Much time is wasted in backbiting. Silence allows one to look within.

\section{Food}

By regulatingyour diet and avoiding bad habits, you can preserve health. This promotes mental poise and also physical happiness. Many people consume more than the necessary quantity of rich food and such has to practice moderation. The food should not be too "hot" or too saltish; there must be a balance and equilibrium maintained. Rajasic food enrages the emotions; thamasic food induces sloth and sleep. Sathwic food satisfies but does not inflame the passions or sharpen the emotions. Acid forming foods are not healthy and alkaline forming foods are bringing balance into the body.

There's no doubt that people who are too fat age faster than people of normal weight. The arteries fill up with plaque, the heart and kidneys work too hard, the gallbladder develops stones, the sex drive declines, cancer and diabetes may develop, the joints develop arthritis because they are overloaded, and the skin stretches.

\section{Meditation - Mind-Emptiness}

The obstacles that one encounters in meditation are physical obstacles, the mental obstacles and the higher obstacles.

The physical obstacles includes:
a) aimless wandering
b) lake of regularity
c) bodily diseases
d) talking too much
e) unfavorable environments
f) fault finding

Among the mental obstacles to meditation are:
a) anger
b) depression
c) doubt
d) evil
e) fear
f) greed
g) hatred

Higher obstacles of meditation include:
a) ambition and desire
b) moral and spiritual
c) religious
d) name and fame
e) elementals
f) visions
g) siddhis
h) strong aloneness
i) sensual bliss
j) memory of pleasure.

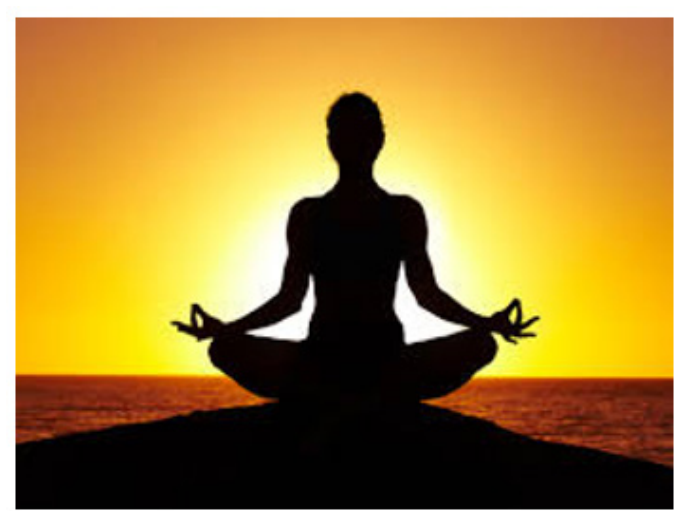


Sara Lazar, a neuroscientist at Massachusetts General Hospital and Harvard Medical School, was one of the first scientists to take the anecdotal claims about the benefits of meditation and mindfulness and test them in brain scans. What she found surprised her - that meditating can literally change your brain. Mind-emptiness means 'empty the mind of all thoughts" and live in now. Time waste is life waste. If we waste time, we are wasting our lives itself. If we are following up with purifications, we live healthy, happier life and sleeping replaces deep meditation. "Besides the practice of Kundalini, what other means is there for clearing away the impurities of the 72,000 nadis" [6]?

\section{Collective Behavior}

Collective behavior is a term used by sociologists to refer to "the ways in which people behave together in crowds, panics, fashions, cults, followings and revolutionary social movements, and other similar groupings. It has been defined as "behavior of individuals" under the influence of an impulse that is common and collective. One of them is collective believe system about aging. Many studies have been made of the spread of rumors, jokes, fads and crazes, hysterical contagion and dramas. This kind of behavior definitely has bad influence on us, and it is not our natural state of mind. We should replace negative thoughts with positive thinking. It has been defined as "the behavior of individuals" under the influence of an impulse that is common and collective, in other words, that is the result of social interaction. It is collective and it's not easy to transform it.

\section{Acknowledgement}

None.

\section{Conflicts of Interest}

No conflicts of interest.

\section{References}

1. William LeGro (1996) Reverse aging. Baca Raton, Globe Communications pp. 85.

2. Rupert Sheldrake (2018) Science and Spiritual Practices. Berkley, California, USA, Counterpoint pp.183.

3. Adam Piore (2019) Scientific American New York, USA, Springer Nature America pp. 54.

4. Herman Pontzer (2019) Scientific American. New York, USA, Springer Nature America pp. 29.

5. Swami Vishnu Devananda (1957) Sivananda Yoga Teachers Manual. Quebec, Canada, Sivananda Ashram Yoga Camp pp. 92.

6. Swami Vishnu Devananda (2008). Hatha Yoga Pradipika. Delhi, India, Motilal Banarsidass pp. 122. 